\title{
CASOS RELEVANTES DE LA SUPREMA CORTE DE JUSTICIA DE MÉXICO EN 2019
}

\author{
Leading cases from the Supreme \\ Court of Mexico in 2019 \\ ALFONSO HERRERA GARCÍA' \\ Universidad Panamericana \\ jaherrerag@yahoo.com.mx
}

Cómo citar/Citation

Herrera García, A. (2020).

Casos relevantes de la Suprema Corte de Justicia de México en 2019.

Anuario Iberoamericano de Justicia Constitucional, 24(2), 593-606.

doi: https://doi.org/10.18042/cepc/aijc.24.21

I. CONSIDERACIÓN INTRODUCTORIA. II. IGUALDAD DE GÉNERO EN LA FAMILIA. III. LIBERTAD SEXUAL EN LA VIDA MATRIMONIAL. IV. PROHIBICIÓN DEL MATRIMONIO INFANTIL. V. FILIACIÓN DE MENORES EN UNIONES HOMOPARENTALES. VI. USO TERAPÉUTICO DE CANNABIS POR NIÑOS CON EPILEPSIA. VII. INCONSTITUCIONALIDAD DE LA INTERDICCIÓN. VIII. INSUFICIENCIA LEGISLATIVA EN MATERIA DE DISCRIMINACIÓN RACIAL. IX. SUPUESTA DISCRIMINACIÓN POR TATUAJE CON CRUZ ESVÁSTICA. X. RECONOCIMIENTO DE LA JURISDICCIÓN ESPECIAL INDÍGENA. XI. DERECHO AL REFUGIO EN TERRITORIO MEXICANO. XII. PORCIONES DEFICIENTES EN LA LEY DE REMUNERACIONES DE SERVIDORES PÚBLICOS. XIII. CONSIDERACIÓN CONCLUSIVA. BIBLIOGRAFÍA.

1 Profesor de Posgrado en Derecho de las Universidades Panamericana e Iberoamericana (Ciudad de México). 


\section{CONSIDERACIÓN INTRODUCTORIA}

A lo largo del 2019, la Suprema Corte de Justicia de la Nación mantuvo un talante jurisprudencial favorable al desarrollo del sistema de derechos fundamentales. En el presente recuento se informan las principales consideraciones de casos relevantes con un doble propósito. El primero y el principal de ellos es su difusión. En segundo lugar, se busca que la identificación de estos criterios facilite posteriores análisis, que profundicen en el trabajo del máximo tribunal mexicano con fines críticos ${ }^{2}$.

La presentación de los casos seleccionados no tiene una lógica secuencial específica. Se presentan por igual asuntos de Salas y del Pleno, con base, desde luego, en su importancia sobresaliente, la novedad que implicaron para la jurisprudencia establecida o por considerarse trascendentes para su divulgación con fines comparativos. Finalmente, el número deliberadamente acotado de los criterios que se describen responde a la necesidad de síntesis y al delimitado espacio que debe destinarse a su exposición.

\section{IGUALDAD DE GÉNERO EN LA FAMILIA}

En el amparo en revisión 331/201933, la Primera Sala declaró inconstitucional una porción del art. 282 del Código Civil del Distrito Federal (Ciudad de México). Este precepto disponía que en los juicios de divorcio la guarda y custodia provisional debía otorgarse automáticamente a la madre cuando los hijos fueran menores de 12 años.

La sentencia es relevante por sí sola en atención a su criterio de fondo. Pero también lo es porque la Sala abandonó un criterio anterior que sostenía la constitucionalidad del artículo con una interpretación conforme. Una de las razones por las cuales superó el precedente fue la modificación de la metodología de análisis.

En el asunto que nos ocupa, la Sala consideró que no era sostenible una interpretación conforme porque la disposición jurídica establecía una distinción normativa basada en una categoría sospechosa enunciada por el artículo $1^{\circ}$ constitucional: una regla de asignación basada en el sexo del progenitor.

De acuerdo con otra línea jurisprudencial de la propia Corte, no es posible declarar la constitucionalidad de un precepto con base en una interpretación

2 Una parte de la selección de los casos aquí expuestos se ha orientado a partir de la realizada en Herrera García, Rivera León y Spigno (2020).

3 Ponente: Juan Luis González Alcántara Carrancá. Sesión del 21 de noviembre, 2019. 
conforme si dicho precepto hace una distinción normativa basada en una cláusula especial de no discriminación.

En el caso, la inconstitucionalidad tiene fundamento en dos razones principales: la vulneración de los principios de igualdad y del interés superior del menor. La disposición de que la madre es quien automáticamente debe hacerse cargo de la guarda y custodia por el simple hecho de ser mujer incurre en un estereotipo de género. Asimismo, profundiza el rol de la mujer y de la madre en la concepción tradicional de la familia. Estos resultados normativos son insostenibles por perpetuar una discriminación histórica.

Por otro lado, el precepto impugnado vulneró el interés superior de la niñez porque desplazaba la función judicial consistente en evaluar las circunstancias particulares de cada caso concreto. Estas condiciones solo pueden garantizarse mediante el proceso intelectivo de la decisión judicial, conforme al cual se dilucidará quién es la persona que puede estar en las mejores condiciones de atender las necesidades afectivas y de cuidado de los hijos. Tal sería el caso, por ejemplo, en que se acreditaran actos de violencia familiar u otros elementos necesarios para determinar el escenario que mejor responda al desarrollo integral de los menores.

Este ejercicio no puede ser ignorado por los juzgadores, quienes deben realizar un análisis de razonabilidad libre de estereotipos de género, que atienda a las circunstancias particulares de cada caso concreto.

En otro asunto, la propia Primera Sala abundó en la salvaguarda de la igualdad entre géneros en el amparo en revisión 1079/2018 ${ }^{4}$. En este caso, declaró la inconstitucionalidad de un precepto del Código Civil del Estado de Chihuahua. El art. 170 de este Código establecía que la administración de los bienes de la sociedad conyugal debía estar a cargo del cónyuge designado para ello. Pero que, en el caso de que hiciera falta esa designación, quien debía ejercer esa función era el cónyuge varón.

La Sala determinó que una norma que excluye a la mujer casada de la administración de la sociedad conyugal o de la representación conyugal es discriminatoria. El efecto normativo generado por ese artículo es denegar a la mujer casada su autonomía legal. Esto trae como consecuencia una disminución de la capacidad jurídica de las mujeres para invocar la protección judicial de sus derechos.

Finalmente, en el mismo ámbito de la igualdad de género, en la acción de inconstitucionalidad 4/2016 , el pleno de la Suprema Corte determinó que, en el caso del mismo Estado de Chihuahua, los hombres en condición de viudez tienen derecho a la pensión de sus cónyuges y a los servicios médicos correspondientes.

4 Ponente: Norma Lucía Piña Hernández. Sesión del 10 de abril, 2019.

5 Ponente: Norma Lucía Piña Hernández. Sesión del 19 de marzo, 2019. 
Los arts. 45, 47 y 69 de la Ley del Instituto Municipal de Pensiones del Estado impedían dichos beneficios cuando no se acreditara una situación de discapacidad total de las personas del sexo masculino. Estos preceptos fueron declarados inconstitucionales por violatorios del principio de igualdad entre hombres y mujeres y, por lo tanto, por incurrir en una discriminación normativa prohibida por el art. $1^{\circ}$ constitucional.

\section{LIBERTAD SEXUAL EN LA VIDA MATRIMONIAL}

Probablemente este caso se encuentre entre los más polémicos de los decididos por la Corte en los últimos tiempos en materia de derecho de familia.

Un hombre demandó a su esposa y a otra persona por la infidelidad sexual que sufrió durante su matrimonio y solicitó la reparación del daño moral por afectación a sus sentimientos, decoro, vida privada, honor y reputación. Las personas demandadas habían mantenido una relación extramarital producto de la cual nació una hija. Este hecho le fue ocultado al demandante por más de veintidós años.

En el amparo directo en revisión 183/2017 ${ }^{6}$, la Primera Sala determinó que la infidelidad no trae como consecuencia una reparación por daño moral. La libertad sexual fue considerada como una expresión del derecho al libre desarrollo de la personalidad. Consiste en la capacidad y posibilidad de decidir con autonomía, sin coerción, ni violencia y con consentimiento pleno, sobre las situaciones, circunstancias, tiempos o personas con las cuales se desean o realizan comportamientos eróticos o sexuales.

En ese sentido, la libertad sexual es un derecho personalísimo que tiene como condición inherente la autonomía en su ejercicio. Es a la propia persona a quien corresponde elegir tener relaciones sexuales con otra, sin mayor límite que el pleno y válido consentimiento de ambas. Por lo tanto, la fidelidad sexual es un deber jurídico de carácter personal y de contenido esencialmente moral: su observancia no puede ser exigida coactivamente.

La Corte estableció que el matrimonio no concede una suerte de derecho o poder coactivo sobre el cuerpo o los actos de la pareja en el ámbito sexual. Aun dentro del matrimonio, las personas casadas conservan la facultad de decidir sobre la práctica de su sexualidad. Cada persona es dueña de su cuerpo y a ella pertenece la libre decisión de buscar el fin del placer sexual, asumiendo

6 Ponente: Norma Lucía Piña Hernández. Si bien este caso fue resuelto en la sesión del 21 de noviembre de 2018, el criterio que de él derivó fue nuevamente motivo de difusión oficial por la Corte el 25 de julio de 2019. 
las consecuencias que esa decisión puede traer a la relación matrimonial que, al mismo tiempo, mantiene.

En consecuencia, la sentencia concluyó que la infidelidad en el matrimonio no puede considerarse como un hecho ilícito del que se desprenda un derecho a indemnización por daño moral bajo un esquema de responsabilidad civil. Considerarlo de esa manera trastocaría el derecho al libre desarrollo de la personalidad y la libertad sexual de las personas, aun dentro de la vida matrimonial.

\section{PROHIBICIÓN DEL MATRIMONIO INFANTIL}

En la acción de inconstitucionalidad 22/2016, el pleno de la Suprema Corte consideró constitucional la derogación de las «dispensas» que estaban previstas en la legislación civil del Estado de Aguascalientes, para que menores de edad estuvieran en la condición jurídica de contraer matrimonio.

La Comisión Estatal de Derechos Humanos del Estado estimaba que la referida derogación en el Código Civil vulneraba los derechos de los menores de edad, especialmente por prohibirles contraer matrimonio en casos "graves y justificados».

La Corte consideró válida la prohibición de esta clase de matrimonios aun en supuestos casos "graves o justificados». La reforma no vulneró el libre desarrollo de la personalidad de los menores de edad, sino que incluso puede entenderse precisamente con el propósito de contribuir al goce de esa libertad.

Tampoco se estimó que la medida legislativa vulnerara la progresividad de los derechos humanos. La reforma buscó proteger el interés superior de la niñez, sin afectar gravemente el derecho a contraer matrimonio al cual todas las personas pueden acceder al alcanzar la mayoría de edad.

Por el contrario, las afectaciones que conlleva el hecho de que los menores de edad contraigan matrimonio son de tal forma graves que no justifican la existencia legal de la dispensa. En consecuencia, la Corte determinó que su derogación constituyó una restricción válida y razonable al acceso al matrimonio y para la protección efectiva de los derechos de la niñez.

\section{FILIACIÓN DE MENORES EN UNIONES HOMOPARENTALES}

En el amparo en revisión 852/2017 ${ }^{8}$, la Primera Sala determinó que la exclusión en el Código Civil del mismo Estado de Aguascalientes de menores de

7 Ponente: Fernando Franco González Salas. Sesión del 26 de marzo, 2019.
8 Ponente: Norma Lucía Piña Hernández. Sesión del 8 de mayo, 2019. 
edad que han nacido en contextos de uniones familiares homoparentales, vulnera el principio del interés superior del menor, el derecho a la identidad, a la igualdad y la no discriminación, así como el derecho a la protección de la familia.

La exclusión normativa también vulnera los derechos de las personas de un mismo sexo a conformar una familia porque limita la filiación jurídica a la circunstancia de que los padres deban tener un distinto género y a un pretendido principio de verdad biológica. En ese sentido, se desconoce la realidad y el derecho de las personas a conformar uniones familiares, las cuales deben ser protegidas en igualdad de condiciones que cualquier otra forma de familia.

En el caso, se precisó que el hijo biológico de una mujer debe poder ser reconocido desde su nacimiento o en acta especial posterior por otra mujer con quien se conformó una unión familiar homoparental, aun cuando evidentemente no exista un vínculo genético con ella. En estas circunstancias, el elemento para establecer la filiación jurídica es la voluntad parental de quien desea ejercer, junto con la madre, la comaternidad. Además, esta es la solución más adecuada para la protección del principio del interés superior de la niñez.

\section{USO TERAPÉUTICO DE CANNABIS POR NIÑOS CON EPILEPSIA}

Un niño fue diagnosticado con epilepsia fármaco-resistente asociada al «síndrome de West». Su médico le prescribió un aceite con cannabidiol (CBD). Sin embargo, el niño generó tolerancia a la sustancia y presentó nuevos síntomas. Estos síntomas pudieron controlarse con una preparación con tetrahidrocannabinol (THC).

En junio de 2017 había entrado en vigor un decreto que reformó diversas disposiciones de la Ley General de Salud para regular el uso del cannabis y sus derivados, para exclusivos fines médicos, entre los que se encontraba el mencionado THC. En el art. cuarto transitorio de ese decreto se dispuso que la Secretaría de Salud armonizaría los reglamentos y la normatividad correspondiente en un plazo de 180 días. Sin embargo, la autoridad fue omisa en dicha armonización.

En el amparo en revisión 57/20199, la Segunda Sala concedió el amparo al menor paciente porque la falta de cumplimiento de la Secretaría de Salud actualizó una omisión reglamentaria que vulneró su derecho fundamental a la protección de su salud. La ausencia de normas reglamentarias que regularan el uso terapéutico de la cannabis le imposibilitó el acceso a un tratamiento basado en la preparación apropiada a sus síntomas.

La Sala estableció que el interés superior del menor en este caso no se limitaba a escucharlo en su calidad de paciente o a brindarle atención médica.

9 Ponente: Eduardo Medina Mora. Sesión del 14 de agosto, 2019. 
Su derecho fundamental se traducía en la asignación de recursos suficientes y la creación de políticas públicas para brindar los servicios médicos de calidad que le fueran necesarios. También para velar por la satisfacción de su bienestar y desarrollo integral, de manera tal que su derecho no se viera limitado o se hiciera prácticamente nugatorio.

La concesión del amparo tuvo dos efectos: a) la orden a la Secretaría de Salud de cumplir con su deber de armonizar las disposiciones reglamentarias para el uso terapéutico de la cannabis y sus derivados en el plazo de 180 días hábiles; y b) garantizar al niño el tratamiento médico integral para tratar su padecimiento.

\section{INCONSTITUCIONALIDAD DE LA INTERDICCIÓN}

La Primera Sala declaró inconstitucionales porciones normativas de los artículos 23 y 450 del Código Civil del Distrito Federal (Ciudad de México) que regulaban el «estado de interdicción». Esta figura había sido decretada en el juicio ordinario civil a una persona con discapacidad intelectual.

En casos como el que ahora se destaca, el estado de interdicción ha sido definido por la Suprema Corte como aquel que exige el nombramiento de un tutor para personas mayores de edad que, por razones de enfermedad o condición de discapacidad, no pueden gobernarse, obligarse o manifestar su voluntad por sí mismas.

En el amparo en revisión 1368/2015 ${ }^{10}$, la Sala argumentó que la figura de la interdicción es excesivamente restrictiva: no permite considerar la posibilidad de que esta sea graduable y proporcional en función de las características y condiciones específicas de las personas.

La sentencia estimó que no puede negarse a las personas con discapacidad, per se, su capacidad jurídica, sino que debe proporcionárseles el apoyo necesario para ejercerla y para tomar sus propias decisiones. Cada tipo de discapacidad requiere medidas específicas a la condición y requerimientos particulares de cada uno. La figura de la interdicción, según la Sala, no permite un significado distinto, acorde a los derechos de las personas mayores o en alguna situación de discapacidad, quienes deben ejercer su autonomía y todos sus derechos con plenitud.

En ese orden de consideraciones, la Sala concluyó que la interdicción es incompatible con el derecho a la igualdad y a la no discriminación, y con el derecho al igual reconocimiento como persona ante la ley, consagrados en el art. $1^{\circ}$ constitucional y 12 de la Convención sobre los Derechos de las Personas con Discapacidad, respectivamente.

10 Ponente: Alfredo Gutiérrez Ortiz Mena. Sesión del 13 de marzo, 2019. 


\section{INSUFICIENCIA LEGISLATIVA EN MATERIA DE DISCRIMINACIÓN RACIAL}

En una demanda de amparo planteada por una asociación civil se señaló como acto reclamado la omisión legislativa del Estado mexicano por no ajustar la legislación al artí. $4^{\mathrm{o}}$ de la Convención Internacional sobre la eliminación de todas las formas de discriminación racial. Esta disposición hace un llamado a declarar ilegales y a prohibir organizaciones, así como actividades organizadas de propaganda y toda actividad que promueva la discriminación racial e incitación a la misma, tales como los discursos de odio racial.

En el amparo en revisión 805/2018 ${ }^{11}$, la Primera Sala advirtió insuficiencias legislativas a partir del señalado mandato internacional, lo cual vulneró el derecho a la no discriminación por condiciones raciales.

La Sala determinó que el Estado mexicano técnicamente no incurrió en una omisión legislativa como se demandaba. El cumplimiento de las obligaciones del Estado mexicano se satisfizo con la expedición de la Ley Federal para Prevenir y Eliminar la Discriminación y con una reforma al Código Penal Federal (adición del art. 149 ter). Pero la Corte consideró que este marco jurídico sí resultó insuficiente en el terreno legislativo, a la luz de un análisis detenido de las exigencias que se deprenden del marco jurídico internacional.

La Ley Federal para Prevenir y Eliminar la Discriminación prohíbe los actos generalmente conocidos como discurso de odio. Pero lo hace de manera insatisfactoria porque solamente confiere al Consejo Nacional para Prevenir la Discriminación la facultad para imponer medidas administrativas y de reparación, sujetando para ello a los servidores públicos a la Ley General de Responsabilidades Administrativas.

Por otro lado, en el art. 149 ter del Código Penal Federal se prevé un amplio elemento subjetivo del delito. En relación con el dolo específico, se actualizaría el delito con la acreditación de cualquier acto «que atente contra la dignidad humana o anule o menoscabe los derechos o libertades». Pero el tipo se limita a la realización de conductas específicas: a) negativa de servicios o prestaciones; b) negativa o restricción de derechos laborales o limitación de servicios de salud; o c) negativa de derechos educativos. Por lo anterior, la Sala determinó la deficiencia del marco normativo federal de cara al cumplimiento de las obligaciones internacionales en la materia y, en consecuencia, concedió el amparo a la asociación civil quejosa.

Este asunto se suma a una línea de jurisprudencia constitucional que ha abierto el camino a la judicialización de construcciones deficientes de marcos legales en materia de discriminación. En este caso, a partir de la aplicación

11 Ponente: Jorge Mario Pardo Rebolledo. Sesión del 30 de enero, 2019. 
directa de un parámetro internacional, que muestra entonces una potencialidad con alcances insospechados en el futuro próximo.

\section{SUPUESTA DISCRIMINACIÓN POR TATUAJE CON CRUZ ESVÁSTICA}

En el amparo directo en revisión 4865/2018 $8^{12}$, la Primera Sala determinó que no es discriminatorio separar del empleo a una persona que porta un tatuaje de una cruz esvástica en el contexto de una empresa privada, en la cual conviviría con personas que se identifican como judías. En este escenario, advirtió que dicho tatuaje actualiza un discurso de odio.

La exhibición de un tatuaje es un acto que corresponde a un ejercicio legítimo de la libertad de expresión. Por tanto, en vía de principio, no debe ser motivo de discriminación en el ámbito laboral. Sin embargo, en el caso concreto, la Sala consideró un conjunto de elementos fácticos que, a su juicio, desvirtuaron la licitud de la expresión representada en el tatuaje en controversia.

En el ámbito cultural mexicano, el tatuaje de una cruz esvástica también representa un discurso de odio racista y antisemita. En los hechos del caso, el tatuaje fue exhibido en una empresa privada de fines comerciales ante empleados y directivos que se identificaron como judíos. En estas condiciones, el referido acto de expresión resulta contrario a la dignidad, la igualdad, la seguridad y la propia expresión de las víctimas, quienes se sintieron violentadas por el portador del tatuaje sin tener el deber jurídico de tolerarlo. Por tanto, se determinó que esa expresión no contaba con cobertura constitucional.

Así, la Sala consideró como lícitas las medidas adoptadas por la empresa demandada, la cual había solicitado al portador del tatuaje que lo cubriera y, ante su negativa, la terminación de la relación laboral, previa liquidación a favor del trabajador cesado en sus labores. Esas medidas no se revelaron como discriminatorias contra el portador del tatuaje y no fue procedente otorgarle la indemnización por daño moral que había solicitado.

\section{RECONOCIMIENTO DE LA JURISDICCIÓN ESPECIAL INDÍGENA}

Integrantes del ayuntamiento indígena ubicado en una comunidad del Estado de Oaxaca (San Cristóbal Suchixtlahuaca) demandaron el reconocimiento del sistema normativo interno de dicha comunidad. La demanda buscaba que el Ministerio Público y el juez ordinario penal se consideraran inhibidos de conocer de hechos en los que debían tener aplicación las normas

12 Ponente: Norma Lucía Piña Hernández. Sesión del 30 de octubre, 2019. 
tradicionales de la comunidad. Los demandantes argumentaron que, de actualizarse la competencia ordinaria penal, se verificaría una interferencia indebida en la decisión de una disputa indígena.

Los hechos estaban relacionados con los daños causados por ganado vacuno en áreas consideradas como prohibidas dentro del territorio de la comunidad. Las autoridades tradicionales indígenas, con base en normas sustantivas y procesales de su orden normativo interno, condenaron a una persona a quien se le atribuyó la responsabilidad de los hechos. La jurisdicción indígena fue incluso aceptada por el individuo desde el inicio del enjuiciamiento. Después, cuando la determinación se reveló en su contra, buscó que la autoridad penal local revocara la decisión.

En el amparo directo $6 / 2018^{13}$, la Suprema Corte adoptó un criterio novedoso para su jurisprudencia constitucional: reconoció por primera vez una jurisdicción especial para los pueblos y comunidades indígenas.

La Primera Sala consideró que, en un caso como este, la aplicación de la jurisdicción especial indígena prevalece sobre la jurisdicción penal. Consideró que es posible identificar esa jurisdicción especial a partir del contexto fáctico dentro de una comunidad indígena y cuando sus autoridades cuentan con normas consuetudinarias al respecto. En especial, como tercer elemento relevante, es dable ese reconocimiento cuando las normas internas no resultan contrarias a los derechos humanos consagrados en la Constitución o en el derecho internacional en esta materia.

En esta tesitura, la Sala no concedió el amparo. Confirmó que la decisión definitiva sería aquella emitida por las autoridades indígenas, tal como lo había decidido la Sala de Justicia Indígena del Estado de Oaxaca, la cual había precisamente determinado que el Ministerio Público y el juez penal debían inhibirse de conocer el caso.

La Primera Sala añadió que esta decisión debía considerarse como parte de la deuda histórica del Estado mexicano a los pueblos y comunidades indígenas y a favor de sus sistemas normativos internos. También señaló que era una decisión acorde con la maximización de su autonomía y autogobierno, en términos del art. $2^{\circ}$ de la Constitución mexicana y de tratados internacionales en materia de derechos humanos de pueblos indígenas y tribales.

\section{DERECHO AL REFUGIO EN TERRITORIO MEXICANO}

Dos personas solicitaron su reconocimiento como refugiados en el Estado mexicano, pero presentaron sus peticiones fuera del plazo reglamentario establecido para ese efecto. Las autoridades negaron la admisión a trámite de

13 Ponente: Juan Luis González Alcántara Carrancá. Sesión del 21 de noviembre, 2019. 
esas solicitudes porque consideraron que los peticionarios no acreditaron una causa ajena a su voluntad que les hubiera impedido presentar dicha solicitud dentro de los 30 días hábiles siguientes a que personas extranjeras ingresen al territorio nacional.

En los amparos en revisión 353/2019 y 399/2019 ${ }^{14}$, la Segunda Sala les concedió la razón. Su conclusión se derivó de la interpretación del Reglamento de la Ley sobre Refugiados y Protección Complementaria, en relación con el estado de vulnerabilidad en la que se encontraban los solicitantes de refugio.

En estas circunstancias, la Corte consideró que el cumplimiento de la disposición reglamentaria referida no debe ser estricta, ni rigurosa. Estimó que no debía exigirse a los peticionarios demostrar, con pruebas documentales, la imposibilidad que habrían tenido para presentar en tiempo sus solicitudes.

La falta de presentación de la solicitud dentro del plazo establecido no debe conducir al desechamiento automático de la solicitud. Para tener por acreditada la imposibilidad para presentar la solicitud dentro del plazo reglamentario, basta acreditar motivos y razones justificadas, esto es, que los hechos manifestados y las pruebas presentadas por los propios solicitantes sean coherentes con el contexto de su propia situación.

\section{PORCIONES DEFICIENTES EN LA LEY DE REMUNERACIONES DE SERVIDORES PÚBLICOS}

El pleno de la Suprema Corte declaró inconstitucionales algunas disposiciones de la Ley Federal de Remuneraciones de los Servidores Públicos. Esta ley había sido reformada para traducir a términos normativos una de las ofertas de campaña de Andrés Manuel López Obrador, presidente de la República desde el 1 de diciembre de 2018. En ese sentido, se trataba para la Corte de un primer caso de resonancias políticas de cara a un prometido nuevo régimen para el país. En este caso, relacionado con la bandera de la «austeridad republicana».

En realidad, desde el 2009, el art. 127 de la Constitución establecía algo que al momento no había alcanzado una solución legislativa satisfactoria: que las retribuciones de los servidores públicos federales no puedan ser superiores a la fijada para el presidente de la República. El impacto que en especial podría tener esa disposición en el Poder Judicial —aunque también en diversos órganos constitucionales autónomos- fue considerado por un sector de la doctrina como un potencial menoscabo a su autonomía e independencia.

14 Ponente: Fernando Franco González Salas. Sesión del 17 de octubre, 2019. 
En las acciones de inconstitucionalidad 105/2018 y 108/2018 ${ }^{15}$, centralmente se argumentaba que la Ley violaba el referido art. 127 constitucional porque permitía discrecionalidad en la fijación de remuneraciones en detrimento de la seguridad jurídica.

El caso suscitó en la Corte particulares complejidades en el proceso de decisión. Una mayoría de 7 ministros (magistrados) — de 11 que la integranse pronunció por la invalidez total de la Ley impugnada. Ese bloque mayoritario consideró que la Ley incurrió en diversas omisiones legislativas consistentes en no establecer parámetros y lineamientos para fijar los salarios del presidente de la República y de otros servidores públicos federales. Advirtió también que la Ley tampoco establecía previsiones adecuadas y aplicables a servidores públicos del Poder Judicial de la Federación.

Esa votación mayoritaria no implicó la declaración de inconstitucionalidad de ese problemático sistema de remuneraciones porque el art. 105 de la Constitución federal exige una votación calificada de 8 votos para conseguir ese resultado en un control abstracto ${ }^{16}$.

Sin embargo, el pleno sí alcanzó 8 votos para declarar la inconstitucionalidad de específicas porciones normativas, atendiéndose a uno de los conceptos torales de invalidez planteados por las demandas: los arts. 6 y 7 de la Ley impugnada permitían a la Cámara de Diputados establecer remuneraciones sin sujetar esa facultad a criterios objetivos y metodológicos que evitaran actos discrecionales, en contra de lo establecido en el referido art. 127 de la Constitución.

La Corte también alcanzó votación calificada para declarar la inconstitucionalidad de los arts. 217 bis y 217 ter del Código Penal Federal. Estos preceptos establecían penas por hacer pagos de sueldos y prestaciones «en exceso» o por no reportar aquéllos «recibidos en exceso». Estas disposiciones se declararon violatorias del principio de taxatividad en materia penal.

Con base en estas razones, la sentencia ordenó al Congreso de la Unión que legislara lo necesario en su más próximo periodo ordinario de sesiones, conforme a los parámetros de la sentencia, considerando la insuficiencia e imprecisión de los arts. $6^{\mathrm{o}}$ y $7^{\mathrm{o}}$ de la Ley ${ }^{17}$.

15 Ponente: Alberto Pérez Dayán. Sesión del 20 de mayo, 2019.

16 Se trata de una disposición que está vigente desde 1995, cuando entró en vigor la reforma a la Constitución que introdujo las acciones de inconstitucionalidad como competencia para el control abstracto de las leyes por la Suprema Corte. Véase Carpizo (1995).

17 En la doctrina se han desarrollado argumentos serios en torno a por qué establecer el salario presidencial como parámetro a los poderes legislativo y judicial resulta problemático desde un punto de vista lógico y jurídico. Véase Aguirre Anguiano (2018). 


\section{CONSIDERACIÓN CONCLUSIVA}

Tras el rápido recuento de las decisiones seleccionadas para esta crónica, corresponde concluir que la jurisprudencia más destacada de la Suprema Corte en el 2019 redundó en pasos adelante para la tutela del sistema de derechos fundamentales. Este año, además, muestra evoluciones considerables en materia de justiciabilidad de las normas por razones de omisión o deficiencias en el terreno legislativo. Esto orienta el rumbo de una actitud judicial menos deferente al legislador, especialmente cuando del principio constitucional a la igualdad y a la no discriminación se trata.

A dos años de que se cumpla una década de la profunda reforma de la Constitución mexicana del 10 de junio de 2011, también se advierte alguna consolidación de técnicas y métodos de interpretación en las sentencias de la Corte, que, en realidad, no podían considerarse de larga experimentación en la vida jurisprudencial de los tribunales del Poder Judicial de la Federación.

Por otro lado, la crisis por la pandemia por COVID-19, como en otras latitudes del mundo, podría implicar pronunciamientos de la Corte relacionados con la tensión inevitable entre los derechos y la emergencia sanitaria. Ello, tomando en consideración que no ha habido un decreto formal de estado de excepción o de emergencia constitucional en el país con motivo de la pandemia, no obstante su drástico impacto en la sociedad mexicana ${ }^{18}$.

Hay que decir también que este año representa tan solo un termómetro preliminar de problemáticas acuciantes que enfrentara la Suprema Corte en los años por venir. Esto es así, en parte, debido al advenimiento de nuevos protagonistas del poder político, tanto en el ámbito del ejecutivo como en el legislativo federal, en donde el partido Morena tiene presencia mayoritaria, habiendo desplazado a partidos que habían dominado el escenario institucional en la historia reciente del país (PRI y PAN).

No es incierto ese potencial escenario considerando que el presidente López Obrador, junto a su movimiento político, ha emprendido profundas transformaciones del sistema político, social, económico y gubernamental en un sexenio que inició en 2018 y que culminará en el 2024, con grandes posibilidades de continuidad en las preferencias del electorado. Los tiempos del Poder Judicial serán entonces tiempos para la observación y la garantía de que esas transformaciones sean compatibles o encuentren adecuado acomodo democrático en el sistema jurídico mexicano.

18 Permítaseme remitir a un análisis sobre esta vigente cuestión: Herrera García (2020). 


\section{Bibliografía}

Aguirre Anguiano, S. S. (2018). ¿Absolutismo constitucional? México: Grupo Creativo SC.

Carpizo, J. (1995). Reformas constitucionales al Poder Judicial Federal y a la jurisdicción constitucional, del 31 de diciembre de 1994. Boletín Mexicano de Derecho Comparado, 83, 807-842. Disponible en: https://bit.ly/34jhD6q.

Herrera García, A. (2020). ¿Ineficacia por omisión? El problema constitucional ante la emergencia pandémica en el caso mexicano. En: C. Landa (coord.). Constitución y emergencia sanitaria, vol. II (pp. 79-89). Lima: Palestra.

Herrera García, A., Rivera León, M. A., y Spigno, I. (2020). México. En R. Albert, D. Landau, P. Faraguna y S. Drugda (eds.). 2019 Global Review of Constitutional Law (pp. 224-228). Chestnut Hill, Massachusetts: I-CONect. 